\title{
Primary tumor immune score fails to predict the prognosis of colorectal cancer liver metastases after hepatectomy in Chinese populations
}

\author{
Hao-Cheng Lin ${ }^{1,2 \#}$, Qiong Shao ${ }^{1,3 \#}$, Jie-Ying Liang ${ }^{1,2 \#}$, Yun Wang ${ }^{1,4}$, Hui-Zhong Zhang ${ }^{1,5}$, Yun-Fei Yuan ${ }^{1,6}$, \\ Bin-Kui Li ${ }^{1,6}$, Xiao-Jun Wu ${ }^{1,7}$, Gong Chen ${ }^{1,7}$, Pei-Rong Ding ${ }^{1,7}$, Zhen-Hai Lu ${ }^{1,7}$, Zhi-Zhong Pan ${ }^{1,7}$, \\ De-Shen Wang ${ }^{1,2}$, Miao-Zhen Qiu ${ }^{1,2}$, Zhi-Qiang Wang ${ }^{1,2}$, Feng-Hua Wang ${ }^{1,2}$, Rui-Hua Xu ${ }^{1,2}$, Yu-Hong Li ${ }^{1,2}$ \\ ${ }^{1}$ State Key Laboratory of Oncology in South China, Sun Yat-sen University Cancer Center, Collaborative Innovation Center for Cancer Medicine, \\ Guangzhou, China; ${ }^{2}$ Department of Medical Oncology, Sun Yat-sen University Cancer Center, Guangzhou, China; ${ }^{3}$ Department of Molecular \\ Diagnostics, Sun Yat-sen University Cancer Center, Guangzhou, China; ${ }^{4}$ Department of Hematologic Oncology, Sun Yat-sen University Cancer \\ Center, Guangzhou, China; ${ }^{5}$ Department of Pathology, Sun Yat-sen University Cancer Center, Guangzhou, China; ${ }^{6}$ Department of Hepatobiliary \\ Surgery, Sun Yat-sen University Cancer Center, Guangzhou, China; ${ }^{7}$ Department of Colorectal Surgery, Sun Yat-sen University Cancer Center, \\ Guangzhou, China \\ Contributions: (I) Conception and design: YH Li, RH Xu, Y Wang; (II) Administrative support: None; (III) Provision of study materials or patients: \\ YF Yuan, BK Li, XJ Wu, G Chen, PR Ding, ZH Lu, ZZ Pan, DS Wang, MZ Qiu, ZQ Wang, FH Wang, HZ Zhang; (III) Collection and assembly \\ of data: HC Lin, Q Shao, JY Liang; (IV) Data analysis and interpretation: HC Lin, Q Shao, JY Liang; (VI) Manuscript writing: All authors; (VII) \\ Final approval of manuscript: All authors. \\ \#These authors contributed equally to this work. \\ Correspondence to: Professor Yu-Hong Li; Rui-Hua Xu. State Key Laboratory of Oncology in South China and Department of Medical Oncology, \\ Sun Yat-sen University Cancer Center, Collaborative Innovation Center for Cancer Medicine, 651 Dongfeng East Road, Guangzhou 510060 , China. \\ Email: liyh@sysucc.org.cn; xurh@sysucc.org.cn.
}

Background: Increasing evidence suggests that the immune score is significantly associated with cancer prognosis. However, the prognostic role of primary tumor immune score in colorectal cancer liver metastases (CRLM) after hepatectomy in Chinese patients has not been reported. The present study is designed to investigate whether the immune score of primary tumor can predict the postoperative survival of liver metastases in Chinese patients.

Methods: A total of 131 patients diagnosed with CRLM were included, and the corresponding primary tumor and liver metastasis specimens were acquired. An immune score ranging from 0 to 4 was established based on the counts and densities of $\mathrm{CD}^{+}$and $\mathrm{CD}^{+} \mathrm{T}$ cells in the core tumor (CT) and the invasive margin (IM). Relapse-free survival (RFS) and overall survival (OS) were analyzed by Kaplan-Meier curves to assess the prognostic role of primary tumor immune score. Furthermore, we conducted a comprehensive search of the Gene Expression Omnibus (GEO) and selected stage IV colorectal cancer (CRC) patients with liver metastasis to compare the tumor-infiltrating $\mathrm{T}$ cell profiles of the primary tumor and liver metastases by CIBERSORT.

Results: Patients with high immune scores in the primary tumor has no significantly better RFS and OS after hepatectomy than those with low immune scores [median RFS (95\% CI): 19.13 (10.07-28.20) vs. 27.13 (15.97-38.29) months, $\mathrm{P}=0.604$; median OS (95\% CI): 64.37 (35.96-92.78) vs. 40.07 (32.54-47.59) months, $\mathrm{P}=0.652]$. Data collected from the GEO indicates that the proportion of $\mathrm{CD}^{+} \mathrm{T}$ cells and total $\mathrm{T}$ cells in the primary tumor and liver metastatic lesion are also not significantly correlated (CD8 ${ }^{+} \mathrm{T}$ cells: $\mathrm{r}^{2}=0.030$, $\mathrm{P}=0.468$; total T cells: $\left.\mathrm{r}^{2}=0.165, \mathrm{P}=0.076\right)$.

Conclusions: The immune score of the primary tumor fails to predict the prognosis of CRLM after hepatectomy in Chinese patients.

Keywords: Colorectal cancer liver metastases (CRLM); tumor infiltrating lymphocytes; immune score; prognosis 
Submitted Jun 25, 2020. Accepted for publication Nov 15, 2020.

doi: 10.21037/atm-20-4932

View this article at: http://dx.doi.org/10.21037/atm-20-4932

\section{Introduction}

Colorectal cancer (CRC) can be a fatal malignancy that has demonstrated an increasing incidence and mortality over the past few decades in China (1), and is currently ranked as the third most common cancer worldwide (2). Synchronous or heterochronous liver metastasis develops in $35-55 \%$ of CRC patients and is the major cause of death $(3,4)$. Liver resection is the main curative treatment for colorectal cancer liver metastasis (CRLM) but more than $60-80 \%$ of the patients experience recurrence after initial liver resection, with a 5 -year survival rate of only $25-50 \%$ (5-8). Clinically, the most widely accepted predictive system for CRLM prognosis after hepatectomy is the clinical risk score (CRS) which was proposed by Fong et al. (9). However, survival varies among patients with the same CRS, suggesting that these clinicopathological parameters are not the only factors influencing survival.

The immune microenvironment plays an important role in the occurrence and progression of CRC. An immune score system, which evaluated the densities of $\mathrm{CD}^{+}$and $\mathrm{CD}^{+}$immune cells in the core tumor (CT) and the invasive margin (IM) of the primary tumor, showed encouraging performance in predicting the postoperative outcome of stage I-III CRC patients (10-12). Previously, both our research and that of Mlecnik B have reported that the immune score for liver metastases can predict the prognosis of CRLM patients who underwent hepatectomy $(13,14)$. Nevertheless, pathological specimens of liver metastases cannot be obtained until liver resection, which limits the practicability of metastatic immune scores in the decision of hepatectomy. We therefore aimed to determine whether the primary tumor immune score could be a substitute for the metastatic immune score to predict prognosis of CRLM patients who underwent liver resection.

In this study, we validate whether the immune score of primary tumor have the potential prognostic value to predict survival outcomes after liver metastases resection and compare the immune infiltration between primary tumor and corresponding liver metastases. We present the following article in accordance with the TRIPOD reporting checklist (available at http://dx.doi.org/10.21037/atm-20-4932).

\section{Methods}

\section{Patients}

Consecutive patients with CRLM who underwent primary tumor resection as well as liver metastasis resection between June 2004 and June 2017 at the Sun Yat-sen University Cancer Center (Guangzhou, China) are included in the present study. The inclusion criteria are as follows: (I) pathologically diagnosed with CRLM; (II) underwent colorectal primary tumor resection as well as synchronous or heterochronous liver metastasis resection with a curative intent; (III) have adequate specimens of both the primary tumor and liver metastasis for immunohistochemical staining; and (IV) have sufficient clinicopathological information for analysis. The exclusion criteria include the following: (I) presence of metastasis outside the liver and (II) previous liver resection history. The study was conducted in accordance with the Declaration of Helsinki (as revised in 2013) of the World Medical Association. The study was approved by the institutional ethical review board of Sun Yat-sen University Cancer Center (Registration number: GZR2019-128) and individual consent for this retrospective analysis was waived.

Decisions on the preoperative chemotherapy protocol and administration before liver resection in the present study were made by the physicians of Sun Yat-sen University Cancer Center. In the current study, patients with CRLM received preoperative oxaliplatin- or irinotecanbased chemotherapy protocols, which included XELOX [capecitabine (Roche, Basel, Switzerland) at $1,000 \mathrm{mg} / \mathrm{m}^{2}$ on D1-D14 and oxaliplatin (Sanofi, Paris, France) $130 \mathrm{mg} / \mathrm{m}^{2}$ intravenous drip (i.v. drip) D1, q3w], FOLFOX [5-FU (Xudong Haipu, Shanghai, China) $2.4 \mathrm{mg} / \mathrm{m}^{2}$ continuous intravenous drip (civ) 46 h, 5-FU (Xudong Haipu, Shanghai, China) $0.4 \mathrm{mg} / \mathrm{m}^{2}$ intravenous injection (i.v.), leucovorin (Wyeth, Madison, NJ, USA) $200 \mathrm{mg} / \mathrm{m}^{2}$ i.v. drip and oxaliplatin (Sanofi, Paris, France) $85 \mathrm{mg} / \mathrm{m}^{2}$ i.v. drip q2w], FOLFIRI [5-FU (Xudong Haipu, Shanghai, China) $2.4 \mathrm{mg} / \mathrm{m}^{2}$ civ $46 \mathrm{~h}, 5-\mathrm{FU}$ (Xudong Haipu, Shanghai, China) $0.4 \mathrm{mg} / \mathrm{m}^{2}$ i.v., leucovorin (Wyeth, Madison, NJ, USA) $200 \mathrm{mg} / \mathrm{m}^{2}$ i.v. drip and irinotecan (Pfizer, New 
York, USA) $180 \mathrm{mg} / \mathrm{m}^{2}$ i.v. drip, q2w] and FOLFIRINOX [5-FU (Xudong Haipu, Shanghai, China) $2.4 \mathrm{mg} / \mathrm{m}^{2}$ civ $46 \mathrm{~h}$, leucovorin (Wyeth, Madison, NJ, USA) $200 \mathrm{mg} / \mathrm{m}^{2}$ i.v. drip, oxaliplatin (Sanofi, Paris, France) $85 \mathrm{mg} / \mathrm{m}^{2}$ i.v. drip, and irinotecan (Pfizer, New York, USA) $180 \mathrm{mg} / \mathrm{m}^{2}$ i.v. drip, $\mathrm{q} 2 \mathrm{w}]$. Molecular-targeted agents, including bevacizumab (Avastin $^{\circledR}$, Roche, Basel, Switzerland) or cetuximab (Erbitux ${ }^{\circledR}$, Merck, Darmstadt, German), were also used in combination with the chemotherapy protocols mentioned above. Bevacizumab was administered at the dosage of $5 \mathrm{mg} / \mathrm{kg}$ i.v. drip every 2 weeks or $7.5 \mathrm{mg} / \mathrm{kg}$ i.v. drip every 3 weeks and was suspended for 6 weeks before and after surgery. Cetuximab was administered at the dosage of $500 \mathrm{mg} / \mathrm{m}^{2}$ i.v. drip every 2 weeks and was only administered in patients with both RAS and BRAF wild type.

\section{Follow-up and data collection}

We performed follow-ups by searching hospital records and making phone contact with the patients or their relatives who are aware of their disease status until October 2017. The routine clinical follow-up was performed by computed tomography or magnetic resonance imaging (MRI) scanning and carcinoembryonic antigen (CEA) and carbohydrate antigen 19-9 (CA19-9) detection every 3 months at Sun Yatsen University Cancer Center or the patients' local hospital. The results were collected from hospital records or by phone contact and patients who were lost from the followup will be excluded from the study. The clinicopathological information of patients in the current study, including age, gender, height, weight, tumor location, histological subtype, tumor grade and $\mathrm{T}$ and $\mathrm{N}$ stage of the primary tumor, was collected from hospital records and was recorded for further analysis. Tumor grade and $\mathrm{T}$ and $\mathrm{N}$ stage of the primary tumor were classified according to the Union for International Cancer Control (UICC) staging system (7th edition). Relapse-free survival (RFS) and overall survival (OS) were calculated from follow-up. Notably, in this study, RFS is defined as the interval from the date of hepatectomy to the date of relapse or metastasis was firstly found by radiographic imaging at any sites or death attributed to any cause other than relapse, and OS is defined as the interval from the date of liver metastasis resection to the date of death attributed to any cause.

\section{Immunobistochemical techniques and image capture}

Paraffin-embedded surgical specimens of both the primary tumor and corresponding liver metastasis of the same patients were collected after surgical resection. In patients with multiple liver lesions, a random metastatic specimen was selected to represent the immune status of all metastases. All of the specimens were sectioned and stained with immunohistochemical techniques that labeled the $\mathrm{CD}^{+}$and $\mathrm{CD}^{+} \mathrm{T}$ cells with specific antibodies: a rabbit anti-CD3 monoclonal antibody (ZSGS-BIO; Beijing, China; catalogue number: ZM-0417; dilution: commercial working solution) and a rabbit anti-CD8 monoclonal antibody (ZSGS-BIO; catalog number: ZA-0508; dilution: commercial working solution). After incubation with primary antibodies at $4{ }^{\circ} \mathrm{C}$ overnight, the slides were treated with a detection reagent mixture that included the corresponding secondary antibody, a streptavidinhorseradish peroxidase complex and diaminobenzidine tetrahydrochloride (DAB) (Dako, Santa Clara, CA, USA; catalog number: K5007) and were incubated in the dark at $37^{\circ} \mathrm{C}$ for 30 minutes. Images of each slide were captured by a Nikon Eclipse 80i microscope (Nikon Corporation, Tokyo, Japan) at $20 \times$ magnification.

\section{Immune score evaluation}

The immune score evaluation was conducted according to Galon J, the establisher of the immune score system $(10,11)$. We used ImageJ, a public domain image analysis program designed by the NIH (National Institute of Health, Bethesda, MD, USA) to assess the densities of positive lymphocytes in the CT area and IM area (15). The CT area is defined as the central area of tumor and the IM area was defined as the area within $0.5 \mathrm{~mm}$ from the tumor boundary (a representative image delineating the CT and IM area is shown in Figure S1). The outline of CT or IM was delineated by polygon selection and the area was calculated automatically (14). Two independent pathologists who were blinded to the clinical information gave assistance to determine the boundaries of CT and IM. DAB color deconvolution was conducted on the image to acquire the brown layer and Threshold Adjust command was carried out to highlight the positive cells. The count and density of positive cells were then calculated automatically by ImageJ. The immune scores were evaluated based on the densities of $\mathrm{CD}^{+}$and $\mathrm{CD}^{+} \mathrm{T}$ cells in the CT or IM of colorectal primary tumors or liver metastatic lesions by using the median densities as a cut-off to define the high or low value of each index $\left(\mathrm{CD}^{+}\right.$in the $\mathrm{CT}, \mathrm{CD}^{+}$in the $\mathrm{IM}, \mathrm{CD}^{+}$in the $\mathrm{CT}$ and $\mathrm{CD}^{+}$in the IM) (14). A high value of each 
index was scored as 1 , while a low value was scored as 0 , and the scores of the 4 indexes were added to calculate the final immune score, which ranged from 0 to $4(10,11)$. Immune scores of primary tumors (immune score PT) and liver metastases (immune score LM) were then calculated and an immune score of 3 to 4 was defined as a high immune score, while a score of 0 to 2 was defined as a low immune score.

\section{Eligible GEO datasets acquisition and microarray data processing}

A comprehensive search of the GEO (https://www.ncbi.nlm. nih.gov/geo/) database was conducted to identify datasets that had data on the following criteria: (I) gene expression profiles of stage IV CRC patients; (II) the primary tumor and liver metastatic lesions; and (III) gene expression profiles that were generated from an Affymetrix Human Genome U133 Plus 2.0 Array or a U133A Array (GPL570 or GP96 platform). Microarray data from 4 datasets, GSE28702, GSE40367, GSE41258, and GSE49355, were used in this study. Raw microarray data (.CEL files) were downloaded and normalized using a robust multiarray averaging method with the "affy" and "simpleaffy" packages (16). The Combat function of the "sva" package was used to remove batch effects (flowchart of data acquisition and sample selection included in the analysis was showed on Figure S2).

\section{Statistical analysis}

Kaplan-Meier curve with log-rank test was used to analyze the predictive value and statistical significance of the immune score PT in predicting RFS and OS after hepatectomy. Subgroup analyses were also carried out by using Kaplan-Meier curve with a log-rank test to compare postoperative survivals in patient with different immune score PT according to whether the patients (I) had synchronous or heterochronous liver metastasis, (II) received preoperative chemotherapy before the primary tumor resection or not, (III) had primary tumor located on right-sided or left-sided. Further, in patients underwent heterochronous resection of primary tumor and liver metastases, subgroup analyses were carried using the Kaplan-Meier curve with log-rank test according to whether pre-hepatectomy chemotherapy was administered or not during the interval between the primary tumor resection and hepatectomy.

Univariate and multivariate Cox regression analyses were performed to screen for potential clinicopathological factors that were related to postoperative survival and to evaluate the prognosis-predictive value of the immune score PT and immune score LM using the hazard ratio (HR) and $95 \%$ confidence intervals (CIs). Further, univariate and multivariate Cox regression analyses were separately performed in patients who underwent heterochronous resection to find out whether the immune score PT has a predictive significance to this specific population.

To further investigate the correlation between immune score PT and immune score LM, the Pearson correlations as well as paired $t$-tests were applied to analyze the correlation and difference of $\mathrm{CD}^{+}$and $\mathrm{CD}^{+} \mathrm{T}$ cell densities between the primary tumor and liver metastasis. To examine the correlation between immune score PT and immune score LM, the Spearman correlation was performed.

In the GEO datasets validation, the normalized gene expression data collected were uploaded to the CIBERSORT web portal (https://cibersort.stanford. $\mathrm{edu} /$ ) and the cell fractions of 22 hematopoietic cell were calculated by the deconvolution algorithm at 1,000 permutations (17). $\mathrm{P}$ values deriving from the CIBERSORT deconvolution of each sample indicated the confidence of the results and only samples with a $\mathrm{P}<0.05$ were included for the immune landscapes comparison between the primary tumors and liver metastases (18). A total of 20 paired samples of CRC primary tumors and corresponding liver metastases were obtained from the GEO and paired $t$-test and Pearson correlation analyses were performed to analyze the difference and correlation between the immune cell proportions of the two sites.

All statistical analyses were carried out by the R software (version 3.6.0) and IBM SPSS software (version 22) using two-tailed tests. $\mathrm{P}$ values $<0.05$ were considered statistically significant.

\section{Results}

\section{Patient characteristics}

A total of 131 patients who were diagnosed with CRLM and underwent radical resection of the primary tumor as well as liver metastases were retrospectively analyzed in this study. Among them, 53 (40.5\%) received preoperative chemotherapy, comprising of 15 (11.5\%) who received the FOLFOX regimen, 25 (19.1\%) who received the XELOX regimen, 5 (3.8\%) who received the FOLFOXIRI regimen, 4 (3.1\%) who received the FOLFIRI regimen, 2 (1.5\%) who 
received bevacizumab in combination with chemotherapy ( 1 in combination with the XELOX regimen and 1 with the FOLFOX regimen) and 2 (1.5\%) who received cetuximab in combination with chemotherapy ( 1 in combination with the FOLFOXIRI regimen and 1 with the FOLFOX regimen).

Of the 131 patients analyzed, $80(61.1 \%)$ were classified as having a low immune score PT, while 51 (38.9\%) were classified as having a high immune score PT. The baseline characteristics of the patients with low and high immune score PT are shown in Table 1. Notably, patients with high immune score PT received a higher proportion of preoperative chemotherapy than the low immune score PT (60.8\% vs. $27.5 \%, \mathrm{P}<0.001)$. In the present study, 75 (57.3\%) patients were classified as having a low immune score LM, and $56(42.7 \%)$ as having a high immune score LM (median densities of the 4 indexes in primary tumor and liver metastases were used as a cut-off and are shown in Table S1). Furthermore, patients were classified into subgroups according to the presence of synchronous metastases, preoperative chemotherapy status, primary tumor location and resection status and the median densities of the 4 indexes in primary tumor of each subgroup were shown in Table S2.

\section{Immune score PT is not correlated to survival in CRLM patients after liver resection}

Of the 131 CRLM patients included in the present study, $74(56.49 \%)$ experienced relapses after radical resection of liver metastases and 43 (32.82\%) died during the followup period (until October 2017). We analyzed the RFS and OS after liver resection according the previous definition of a high immune score PT (3 to 4 ) and a low immune score PT (0 to 2). The RFS is not significantly different between patients with a high immune score PT and a low immune score PT [median RFS (95\% CI): 19.13 (10.07-28.20) vs. 27.13 (15.97-38.29) months, $\mathrm{P}=0.604]$. Similarly, the OS of patients with a high immune score PT is not significantly better than that of those with a low immune score PT [median OS (95\% CI): 64.37 (35.96-92.78) vs. 40.07 (32.54-47.59) months, $\mathrm{P}=0.652$ ] (Figure 1A,B).

Subgroup analyses were carried out according to (I) the presence of synchronous liver metastases, (II) preoperative chemotherapy status before the primary tumor resection, (III) primary tumor location, and (IV) resection status. A total of 114 (87.0\%) patients had synchronous liver metastases. Patients with low immune score PT have no significant difference in OS or RFS when compared to patients with high immune score PT, regardless of their lesions being synchronous or heterochronous metastases. Patients with different preoperative chemotherapy statuses were also analyzed. Of the 53 (40.5\%) CRLM patients who received preoperative chemotherapy before primary tumor resection, the low immune score PT patients show a tendency to have a worse OS and RFS but this difference is not statistically significant. Meanwhile, of the 78 (59.5\%) patients who did not receive preoperative chemotherapy, those with low immune score PT show no significant difference in RFS or OS in comparison with those of high immune score. Similarly, the low immune score patients show no significant difference in RFS or OS when compared with high immune score patients, regardless of their primary tumor being right- or left-sided. Notably, in subgroup analyses classifying patients according to resection status and found that no significant difference in OS or RFS is observed between the low and high immune score patients, regardless of the resections of primary tumor and liver metastasis are synchronous or heterochronous.

Subgroup analyses were further carried out separately in patients who received heterochronous resection with different pre-hepatectomy chemotherapy status. In patients who had no pre-hepatectomy chemotherapy during the interval between primary tumor resection and hepatectomy, low immune score PT is found to be associated with both shorter OS and RFS without any statistical significance observed. In patients who received pre-hepatectomy chemotherapy, low immune score PT is related to shorter OS and RFS without statistical significance either. RFS and OS of subgroup analysis mentioned above are shown in Table 2.

The classification according to immune score for liver metastasis revealed that patients with high immune score LM present with prolonged RFS and OS when compared to patients with low immune score LM, and the OS difference is statistically significant [median RFS (95\% CI): 30.50 (13.72-42.78) vs. 12.70 (2.71-22.96) months, $\mathrm{P}=0.054$; median OS (95\% CI): 79.20 (40.83-117.58) vs. 37.57 (26.93-48.21) months, $\mathrm{P}=0.003$ ] (Figure $1 C, D$ ).

\section{Univariate and multivariate analyses of prognostic factors}

Univariate analysis revealed that patients with a high immune score LM is estimated to have a $59.5 \%$ lower risk of death compare to patients with a low immune score LM (HR: $0.405,95 \%$ CI: $0.222-0.737, \mathrm{P}=0.003$ ) and remain 
Table 1 Clinicopathological characteristics of patients with colorectal cancer liver metastases according to immune score PT

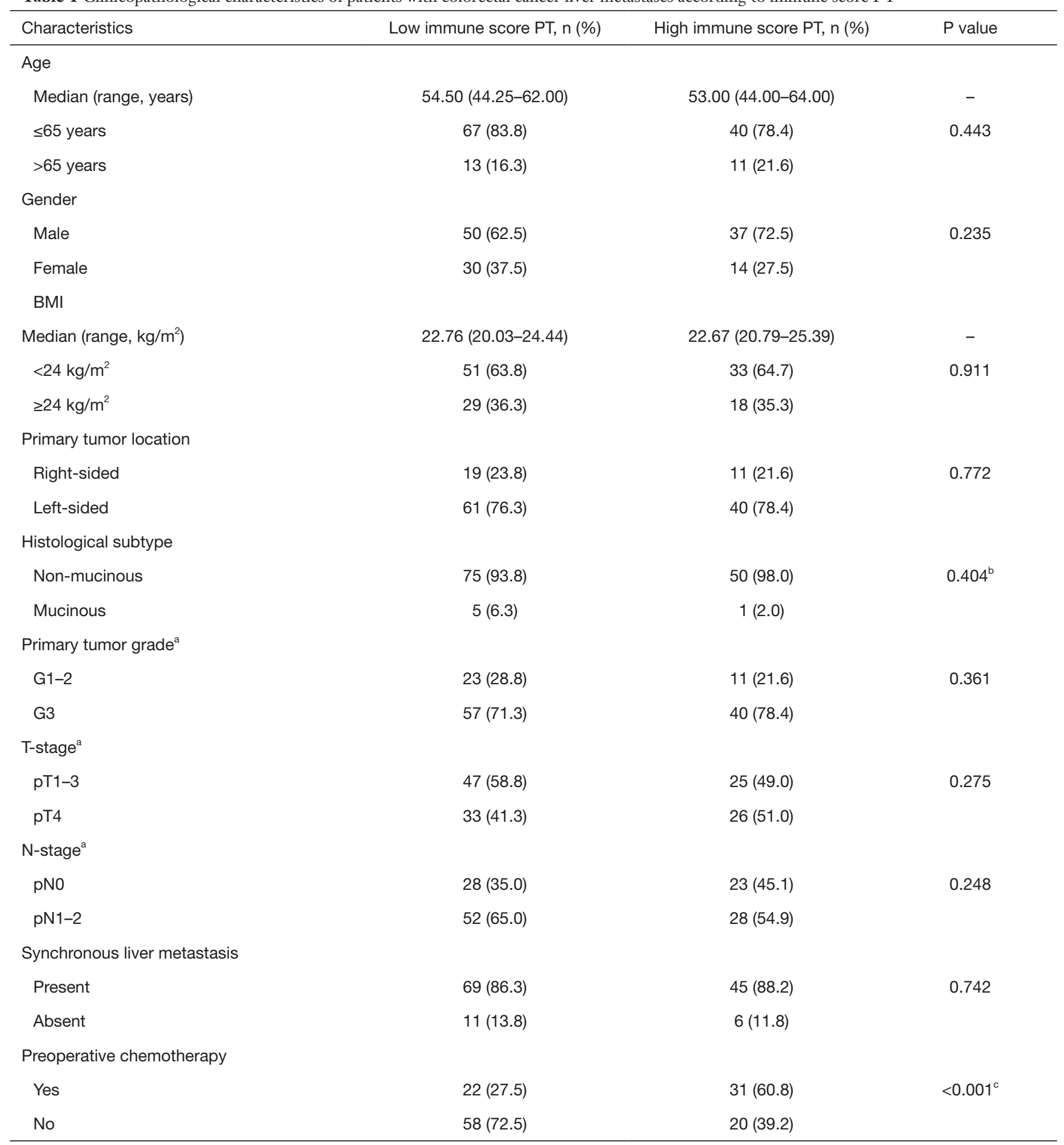

${ }^{\mathrm{c}}$, according to Union for International Cancer Control (UICC) staging system (7th edition); ${ }^{\mathrm{d}}$, Fisher's exact test; ${ }^{\mathrm{e}}$, difference with a P value $<0.05$ was considered statistically significant and showed in bold. PT, primary tumor; BMI, body mass index. 

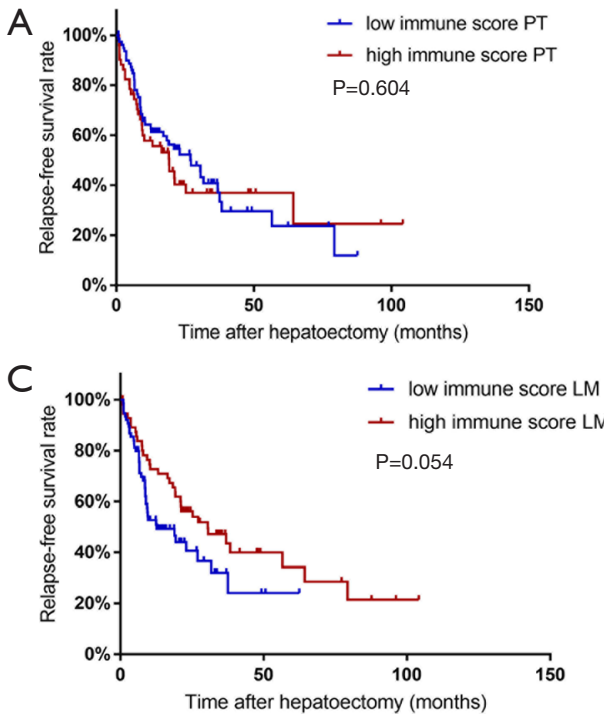
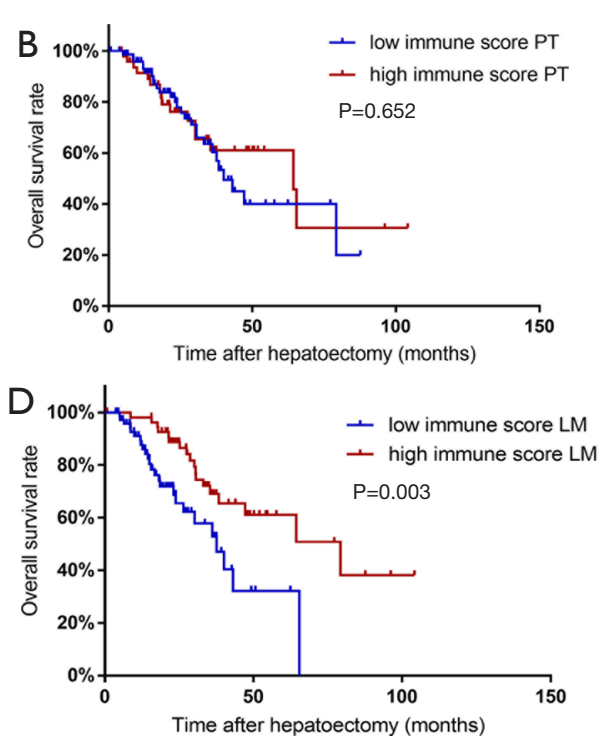

Figure 1 Survival curves of RFS (A,C) and OS (B,D) in patients with high and low immune score PT values (A,B) and LM values (C,D). RFS, relapse-free survival; OS, overall survival; PT, primary tumor; LM, liver metastases.

statistically significant after adjusting for clinicopathological factors including age, gender, body mass index (BMI), grade, primary tumor location, $\mathrm{T}$ and $\mathrm{N}$ stage of primary tumor, synchronous or heterochronous metastasis, synchronous or heterochronous resection and preoperative chemotherapy status in multivariate Cox regression analyses (HR: 0.507, 95\% CI: 0.261-0.983, P=0.044). High immune score LM also confers a $38.3 \%$ lower risk of relapse compared to low immune score LM in univariate analysis. High immune score PT is estimated to confer a better OS and RFS in multivariate analysis but neither reached statistical significance. Other clinicopathological factors indicating worse postoperative survival in multivariate analysis include G3 primary tumor grade, preoperative chemotherapy in OS and heterochronous resection in RFS (predictive factors for RFS in all patients are shown in Table 3 and predictive factors for OS are shown in Table 4). The regression coefficients in multivariate Cox regression of Tables 3,4 are shown in Table S3.

Multivariate analyses performed separately in patients who underwent heterochronous resection reveal that high immune score LM predicts $57.1 \%$ lower risk of relapse and $66.0 \%$ lower risk of death when compared with low immune score LM (RFS: HR: 0.429, 95\% CI: 0.208-0.882, $\mathrm{P}=0.021$; OS: HR: $0.340,95 \%$ CI: $0.130-0.889, \mathrm{P}=0.028$ ), but high immune score PT confers no significant benefit in RFS or OS. Other clinicopathological factors indicating worse postoperative survival in multivariate analysis include preoperative chemotherapy before hepatectomy in RFS and $\mathrm{BMI} \geq 24 \mathrm{~kg} / \mathrm{m}^{2}$, G3 primary tumor grade, preoperative chemotherapy before primary tumor resection or metastasis resection in OS (predictive factors for RFS in patients underwent heterochronous resection are shown in Table 5 and predictive factors for OS are shown in Table 6).

\section{Correlation between immune score PT and immune score $L M$}

Four immune score indexes $\left(\mathrm{CD}^{+}\right.$cells in the $\mathrm{CT}, \mathrm{CD}^{+}$ cells in the IM, $\mathrm{CD}^{+}$cells in the CT, and $\mathrm{CD}^{+}$cells in the IM) were compared between both the primary tumor and metastatic liver specimens, and Pearson correlation analyses were performed (a representative image of the 4 indexes is shown in Figure 2). The $\mathrm{CD}^{+}$and $\mathrm{CD}^{+} \mathrm{T}$ cell densities in the primary tumor specimens are higher than those in the metastatic liver specimens in both the CT and IM areas (Figure 3). Pearson correlation analysis shows no significant association between the densities of $\mathrm{CD}^{+} \mathrm{T}$ cells in the primary tumor and liver metastasis $\left(C T\right.$ : $\mathrm{r}^{2}<0.001, \mathrm{P}=0.971$; IM: $\mathrm{r}^{2}=0.016, \mathrm{P}=0.152$; Figure $\left.4 A, B\right)$ in both the CT and IM areas. Similarly, significant correlations are not observed in the $\mathrm{CD}^{+} \mathrm{T}$ cell densities between the primary tumor and metastatic liver specimens in either the CT or IM areas (CT: $\mathrm{r}^{2}<0.001, \mathrm{P}=0.809 ;$ IM: $\mathrm{r}^{2}=0.004, \mathrm{P}=0.483 ;$ Figure $\left.4 C, D\right)$. Furthermore, Spearman analysis also finds no significant correlation between immune score $\mathrm{PT}$ and immune score $\mathrm{LM}\left(\mathrm{r}^{2}<0.001, \mathrm{P}=1.000\right)$. 
Table 2 Relapse-free survivals and overall survivals in subgroup analysis according to clinicopathological factors

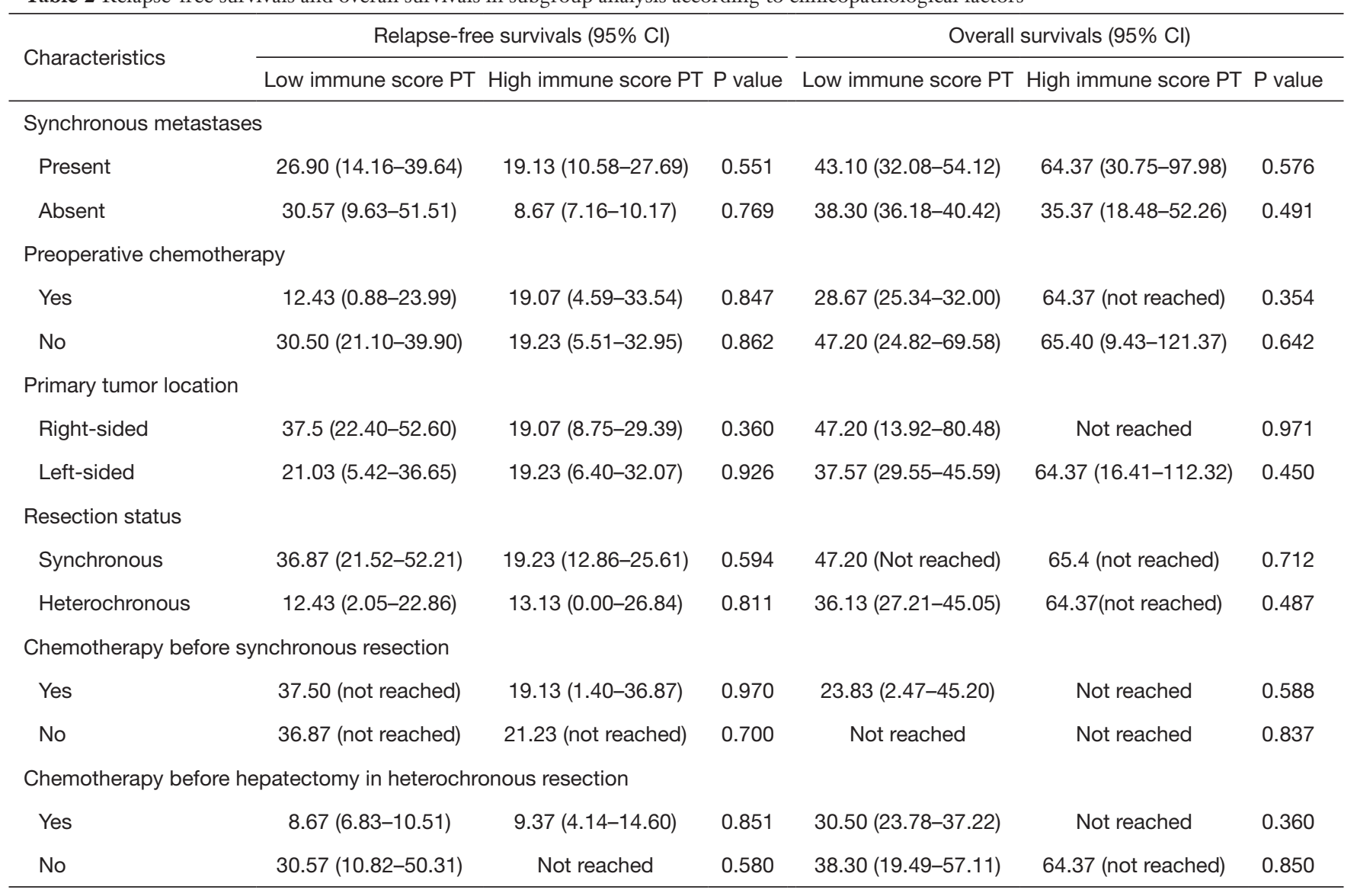

$\mathrm{Cl}$, confidence interval; $\mathrm{PT}$, primary tumor.

\section{GEO dataset validation}

The landscape of 22 subpopulations of immune cells infiltrating the primary tumor and liver metastasis was obtained from 117 stage IV CRC primary tumors and 58 liver metastases and was summarized by the CIBERSORT algorithm (Figure 5A,B). Notably, liver metastases are infiltrated by a higher proportion of memory B cells, activated NK cells, M2 macrophages and neutrophils in comparison to primary tumors, whereas the proportion of naïve B cells, plasma cells, and activated dendritic cells is relatively lower. However, no significant difference is observed in the proportion of total $\mathrm{T}$ cells $\left(\mathrm{CD}^{+} \mathrm{T}\right.$ cells) or $\mathrm{CD}^{+} \mathrm{T}$ cells (Figure 5C,D).

Of the 20 paired samples of CRC primary tumors and corresponding liver metastases obtained from the GEO, paired $t$-test and Pearson correlation analyses were performed. Our findings show no significant difference or correlation between the proportion of $\mathrm{CD}^{+} \mathrm{T}$ cells or total $\mathrm{T}$ cells $\left(\mathrm{CD}^{+} \mathrm{T}\right.$ cells $)$ in the primary tumor and liver metastatic lesions $\left(\mathrm{CD}^{+} \mathrm{T}\right.$ cells: $\mathrm{r}^{2}=0.165, \mathrm{P}=0.076$; $\mathrm{CD}^{+}$ T cells: $\mathrm{r}^{2}=0.030, \mathrm{P}=0.468$, shown in Figure 5E,F,G,H).

\section{Discussion}

In the present study, our findings reveal that the immune score of primary tumor is not related to neither OS nor RFS after hepatectomy in Chinese patients with CRLM, regardless of metastasis being synchronous or heterochronous, preoperative chemotherapy status or primary tumor location. Immune score PT also shows no significant association with post-hepatectomy survivals in patients who underwent heterochronous resection with different pre-hepatectomy chemotherapy status. However, consistent with both our reports and that of Mlecnik B, the present results of multivariate Cox regression analysis suggest that patients with 
Table 3 Predictive factors for relapse-free survival by univariate and multivariate analysis in all patients

\begin{tabular}{|c|c|c|c|c|}
\hline Characteristics & \multicolumn{2}{|c|}{ Univariate analysis } & \multicolumn{2}{|c|}{ Multivariate analysis } \\
\hline \multicolumn{5}{|l|}{ Age } \\
\hline$>65$ vs. $\leq 65$ years & $0.650(0.343-1.232)$ & 0.186 & $0.780(0.398-1.528)$ & 0.469 \\
\hline \multicolumn{5}{|l|}{ Gender } \\
\hline \multicolumn{5}{|l|}{ BMI } \\
\hline$\geq 24$ vs. $<24 \mathrm{~kg} / \mathrm{m}^{2}$ & $1.378(0.866-2.192)$ & 0.176 & $1.438(0.867-2.387)$ & 0.159 \\
\hline \multicolumn{5}{|l|}{ Primary tumor grade ${ }^{a}$} \\
\hline G3 vs. G1-2 & $1.136(0.680-1.900)$ & 0.626 & $1.149(0.672-1.965)$ & 0.612 \\
\hline \multicolumn{5}{|l|}{ T-stage $^{a}$} \\
\hline pT4 vs. pT1-3 & $1.466(0.936-2.295)$ & 0.094 & $1.441(0.878-2.364)$ & 0.148 \\
\hline \multicolumn{5}{|l|}{$\mathrm{N}$-stage ${ }^{\mathrm{a}}$} \\
\hline pN1-2 vs. pNo & $1.749(1.073-2.850)$ & $0.025^{\mathrm{b}}$ & $1.452(0.867-2.434)$ & 0.157 \\
\hline \multicolumn{5}{|l|}{ Synchronous metastases } \\
\hline Present vs. absent & $0.930(0.500-1.731)$ & 0.820 & $0.577(0.281-1.186)$ & 0.135 \\
\hline \multicolumn{5}{|l|}{ Resection status } \\
\hline Heterochronous vs. synchronous & $1.803(1.144-2.840)$ & $0.011^{\mathrm{b}}$ & $1.850(1.081-3.165)$ & $0.025^{b}$ \\
\hline High vs. low & $1.115(0.707-1.759)$ & 0.640 & $0.986(0.577-1.684)$ & 0.958 \\
\hline
\end{tabular}

a , according to Union for International Cancer Control (UICC) staging system (7th edition); ${ }^{\mathrm{b}}, \mathrm{P}$ value $<0.05$ was defined as statistically significant. BMI, body mass index; LM, liver metastases; PT, primary tumor.

higher immune score LM can predict the prognosis of CRLM patients who underwent hepatectomy, implying the immune heterogeneity between primary and liver metastatic sites.

Difference and correlation of immune infiltration between the primary tumor and metastatic lesions have been studied and discussed in the past decade, but the results are still controversial. A retrospective study involving 24 metastatic CRC (mCRC) patients with lung and liver metastases reported that infiltrating $\mathrm{CD}^{+}, \mathrm{CD}^{+}$and $\mathrm{FOXP}^{+}$ $\mathrm{T}$ cell densities in primary CRC were significantly associated with those in lung and liver metastasis lesions (19). Similarly, small sample research of breast cancer also reported the resemblance of types of tumor-infiltrating lymphocytes (TILs) in any metastasis and corresponding primary tumors (20). However, a retrospective study focusing on mCRC with liver-exclusive metastasis found that there was a significantly heterogeneous distribution of $\mathrm{CD}^{+}$, $\mathrm{CD}^{+}$, and granzyme $\mathrm{B}^{+}$lymphocytes between the primary tumor and liver metastasis but no evident correlation was observed (21). Recently, a large sample retrospective study 
Table 4 Predictive factors for overall survival by univariate and multivariate analysis in all patients

\begin{tabular}{|c|c|c|c|c|}
\hline Characteristics & \multicolumn{2}{|c|}{ Univariate analysis } & \multicolumn{2}{|c|}{ Multivariate analysis } \\
\hline \multicolumn{5}{|l|}{ Age } \\
\hline$>65$ vs. $\leq 65$ years & $1.154(0.573-2.324)$ & 0.688 & $1.440(0.656-3.159)$ & 0.363 \\
\hline \multicolumn{5}{|l|}{ Gender } \\
\hline \multicolumn{5}{|l|}{ BMI } \\
\hline$\geq 24$ vs. $<24 \mathrm{~kg} / \mathrm{m}^{2}$ & $1.809(1.002-3.266)$ & $0.049^{b}$ & $1.694(0.876-3.276)$ & 0.117 \\
\hline \multicolumn{5}{|l|}{ Primary tumor grade ${ }^{a}$} \\
\hline G3 vs. G1-2 & $2.301(1.235-4.286)$ & $0.009^{b}$ & $2.419(1.249-4.683)$ & $0.009^{b}$ \\
\hline \multicolumn{5}{|l|}{ T-stage $^{a}$} \\
\hline pT4 vs. pT1-3 & $1.301(0.735-2.302)$ & 0.367 & $1.564(0.807-3.035)$ & 0.185 \\
\hline \multicolumn{5}{|l|}{$\mathrm{N}$-stage ${ }^{\mathrm{a}}$} \\
\hline pN1-2 vs. pNo & $1.695(0.913-3.145)$ & 0.095 & $1.087(0.545-2.169)$ & 0.812 \\
\hline \multicolumn{5}{|l|}{ Synchronous metastases } \\
\hline Present vs. absent & $1.388(0.704-2.736)$ & 0.343 & $0.738(0.321-1.697)$ & 0.475 \\
\hline \multicolumn{5}{|l|}{ Resection status } \\
\hline Heterochronous vs. synchronous & $1.687(0.931-3.057)$ & 0.085 & $1.961(0.939-4.094)$ & 0.073 \\
\hline \multicolumn{5}{|c|}{ Preoperative chemotherapy before primary tumor resection } \\
\hline High vs. low & $0.802(0.443-1.452)$ & 0.465 & $0.636(0.314-1.288)$ & 0.209 \\
\hline
\end{tabular}

a , according to Union for International Cancer Control (UICC) staging system (7th edition); ${ }^{\mathrm{b}}, \mathrm{P}$ value $<0.05$ was defined as statistically significant. BMI, body mass index; LM, liver metastases; PT, primary tumor.

comparing the immune infiltration of $\mathrm{CD}^{+}, \mathrm{CD}^{+}, \mathrm{CD} 20^{+}$,

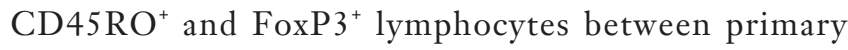
tumors and metastases based on European population also reported that primary and corresponding metastatic lesion have a heterogeneous immune environment (22). In the present study, we involved CRLM patients who underwent liver resection, to make comparison between the immune infiltration of primary tumor and corresponding liver metastasis by evaluating $\mathrm{CD}^{+}$(representing total infiltrating $\mathrm{T}$ lymphocytes) and $\mathrm{CD} 8^{+}$(representing cytotoxic $\mathrm{T}$ lymphocytes) $\mathrm{T}$ cells densities, by which the immune score was calculated. Our observation supports that immune infiltration between primary tumor and corresponding liver-exclusive metastasis is highly heterogeneous in Chinese population and is further supported by validation using the GEO datasets. The densities of $\mathrm{CD}^{+}$and $\mathrm{CD}^{+}$ lymphocytes in primary tumor are significantly higher than those in liver metastases but no correlation is observed in between. Although the immune infiltrates in liver metastases predict post-hepatectomy survivals, the immune 
Table 5 Predictive factors for relapse-free survival by univariate and multivariate analysis in patients underwent heterochronous resection

\begin{tabular}{|c|c|c|c|c|}
\hline Characteristics & \multicolumn{2}{|c|}{ Univariate analysis } & \multicolumn{2}{|c|}{ Multivariate analysis } \\
\hline \multicolumn{5}{|l|}{ Age } \\
\hline$>65$ vs. $\leq 65$ years & $0.316(0.096-1.041)$ & 0.058 & $0.478(0.116-1.964)$ & 0.306 \\
\hline \multicolumn{5}{|l|}{ Gender } \\
\hline \multicolumn{5}{|l|}{$\mathrm{BMI}$} \\
\hline$\geq 24$ vs. $<24 \mathrm{~kg} / \mathrm{m}^{2}$ & $1.257(0.689-2.294)$ & 0.455 & $1.982(0.967-4.063)$ & 0.062 \\
\hline \multicolumn{5}{|l|}{ Primary tumor grade ${ }^{a}$} \\
\hline G3 vs. G1-2 & $1.390(0.682-2.832)$ & 0.365 & $1.692(0.669-4.281)$ & 0.267 \\
\hline \multicolumn{5}{|l|}{ T-stage $^{a}$} \\
\hline pT4 vs. pT1-3 & $1.430(0.777-2.631)$ & 0.250 & $1.299(0.609-2.770)$ & 0.498 \\
\hline \multicolumn{5}{|l|}{$\mathrm{N}$-stage ${ }^{a}$} \\
\hline pN1-2 vs. pNo & $1.164(0.621-2.182)$ & 0.635 & $0.831(0.390-1.770)$ & 0.632 \\
\hline \multicolumn{5}{|c|}{ Preoperative chemotherapy before primary tumor resection } \\
\hline Yes vs. no & $1.227(0.668-2.257)$ & 0.510 & $1.380(0.564-3.377)$ & 0.481 \\
\hline \multicolumn{5}{|c|}{ Preoperative chemotherapy before liver resection } \\
\hline Yes vs. no & $3.074(1.442-6.555)$ & $0.004^{b}$ & $3.479(1.421-8.518)$ & $0.006^{b}$ \\
\hline
\end{tabular}

a , according to Union for International Cancer Control (UICC) staging system (7th edition); ${ }^{\mathrm{b}}$, P value $<0.05$ was defined as statistically significant. BMI, body mass index; LM, liver metastases; PT, primary tumor.

infiltration in primary tumor show no association with prognosis of hepatectomy. Controversies of the results of previous reports may be caused by the difference in sample size and study design. Studies that reported metastatic lesion shared a similar immune infiltration with primary tumors involved a relatively small population of patients and analyzed metastasis at all sites. However, large sample retrospective studies involving liver-exclusive or liverdominated metastasis reported that the immune infiltration was highly heterogeneous between primary tumor and liver metastasis.

The mechanisms underlying the different immune infiltration between the primary tumor and liver metastases remain unclear (23). One hypothesis suggested that chemotherapy may change the immune microenvironment and lead to the difference between primary tumor and metastases, since the cytotoxic effect of preoperative chemotherapy can cause the death of tumor cells and release antigen, resulting in enhanced immune infiltration (22). Our present study shows that patients with high immune score $\mathrm{PT}$ have a higher proportion of receiving preoperative chemotherapy than patients with low immune score PT, indicating that chemotherapy may alter the immune infiltration. Other previous studies have reported that in patients who underwent heterochronous resection and received pre-hepatectomy chemotherapy during the 
Table 6 Predictive factors for overall survival by univariate and multivariate analysis in patients underwent heterochronous resection

\begin{tabular}{|c|c|c|c|c|}
\hline Characteristics & \multicolumn{2}{|c|}{ Univariate analysis } & \multicolumn{2}{|c|}{ Multivariate analysis } \\
\hline \multicolumn{5}{|l|}{ Age } \\
\hline$>65$ vs. $\leq 65$ years & $0.357(0.083-1.536)$ & 0.166 & $1.121(0.200-6.285)$ & 0.896 \\
\hline \multicolumn{5}{|l|}{ Gender } \\
\hline \multicolumn{5}{|l|}{ BMI } \\
\hline$\geq 24$ vs. $<24 \mathrm{~kg} / \mathrm{m}^{2}$ & $1.655(0.782-3.502)$ & 0.188 & $2.656(1.066-6.618)$ & $0.036^{\mathrm{b}}$ \\
\hline \multicolumn{5}{|l|}{ Primary tumor grade ${ }^{a}$} \\
\hline G3 vs. G1-2 & $2.321(1.010-5.332)$ & $0.047^{\mathrm{b}}$ & $5.400(1.675-17.414)$ & $0.005^{\mathrm{b}}$ \\
\hline \multicolumn{5}{|l|}{ T-stage ${ }^{a}$} \\
\hline pT4 vs. pT1-3 & $1.304(0.612-2.777)$ & 0.491 & $1.440(0.537-3.862)$ & 0.468 \\
\hline \multicolumn{5}{|l|}{$N$-stage ${ }^{a}$} \\
\hline pN1-2 vs. pNo & $1.273(0.588-2.755)$ & 0.540 & $0.553(0.195-1.567)$ & 0.265 \\
\hline \multicolumn{5}{|c|}{ Preoperative chemotherapy before liver resection } \\
\hline Yes vs. no & $1.289(0.614-2.703)$ & 0.502 & $4.167(1.362-12.743)$ & $0.012^{b}$ \\
\hline \multicolumn{5}{|c|}{ Preoperative chemotherapy before liver resection } \\
\hline Yes vs. no & $1.646(0.717-3.779)$ & 0.240 & $3.280(1.088-9.886)$ & $0.035^{\mathrm{b}}$ \\
\hline
\end{tabular}

a , according to Union for International Cancer Control (UICC) staging system (7th edition); ${ }^{\mathrm{b}}, \mathrm{P}$ value $<0.05$ was defined as statistically significant. BMI, body mass index; LM, liver metastases; PT, primary tumor.

interval between primary tumor resection and hepatectomy, liver metastases may have immune landscapes different from primary tumor $(13,22)$. However, our results also show that immune score PT fails to predict postoperative survival and do not correlate to immune score LM in patients who received synchronous resection, nor in patients who received heterochronous resection without pre-hepatectomy chemotherapy during the interval between primary tumor resection and hepatectomy. A possible hypothesis may be that metastatic tumor cells were originate from different malignant clones derived from the primary tumor and are characterized by significantly different genetic and epigenetic alterations compared to the primary tumor during the metastatic process, causing the heterogenous immune landscapes observed between the primary tumor and liver metastases (24-27). Our analysis of the GEO datasets also suggests that immune infiltration for liver metastasis tend to have a lower proportion of antigen presenting cells and higher proportion of $\mathrm{M} 2$ protumor phenotype macrophages, implying that immune suppression in liver metastasis may be more obvious than in primary tumor. Notably, this significant heterogeneity was observed in liver-exclusive or -dominated metastasis, implying that the distinct interactions between the hepatic microenvironment and metastatic tumor cells may contribute to this phenomenon $(28,29)$. 


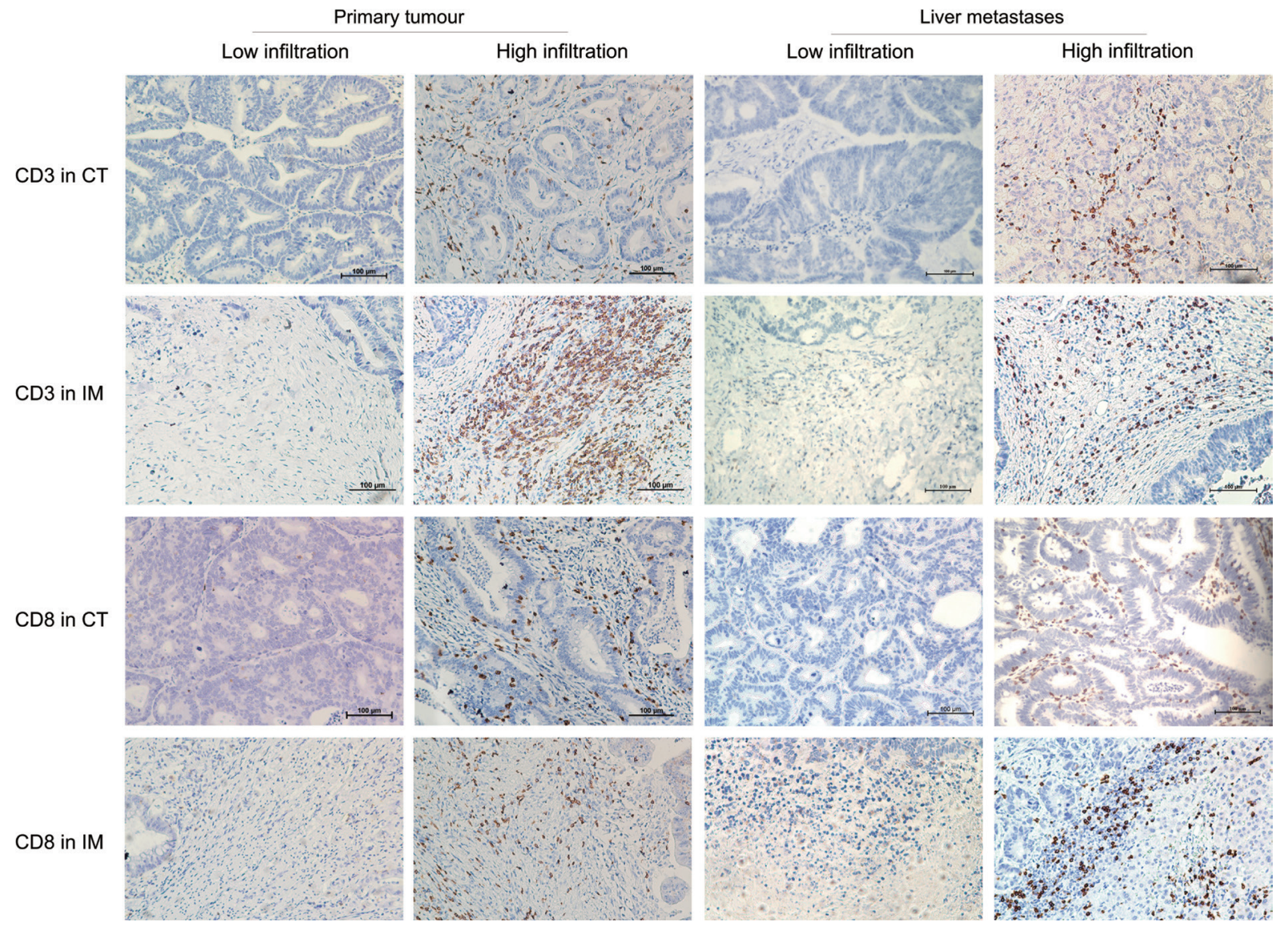

Figure 2 Representative pictures of low and high densities of $\mathrm{CD}^{+}$and $\mathrm{CD}^{+} \mathrm{T}$ cells infiltrated in core tumor (CT) and invasive margin (IM). The two columns on the left were images captured from colorectal primary tumor and the two columns on the right were images captured from liver metastases (right) (IHC stain, scale bar $=100 \mu \mathrm{m}$ ). CT, core tumor; IM, invasive margin.

Multivariate Cox regression analyses showed that in addition to low immune score LM, other clinicopathological factors including G3 primary tumor grade and receiving preoperative chemotherapy are related to worse postoperative OS. However, patients who received preoperative chemotherapy are more likely to present with unfavorable clinicopathological factors, such as higher CRS scores which may contribute to the high risk of recurrence and short postoperative survival.

Several limitations of the current study need to be mentioned. Firstly, this study was designed retrospectively and only involved samples from a single institution which may have caused selection bias and impair the stringency of the findings. Secondly, the present study focused on only two immune indexes (CD3 and CD8). To further evaluate the predictive value of primary tumor immune status, a comprehensive analysis of the overall immune status between primary and liver metastatic lesions are needed. In addition, the underlying mechanisms causing the discordance between the immune score of the primary tumor and that of liver metastases were not elucidated in this study.

However, to our knowledge, the present study is the first to evaluate the value of the primary tumor immune score in predicting the survival of CRLM after hepatectomy in Chinese patients. Primary tumor immune score fails to predict prognosis after hepatectomy and no significant correlation is observed between the immune status of primary tumor and liver metastasis. Future studies are required to make a comparison between immune status of primary and metastatic lesion and fundamental research is needed to thoroughly elucidate the mechanism of different lymphocytes infiltration formation. 

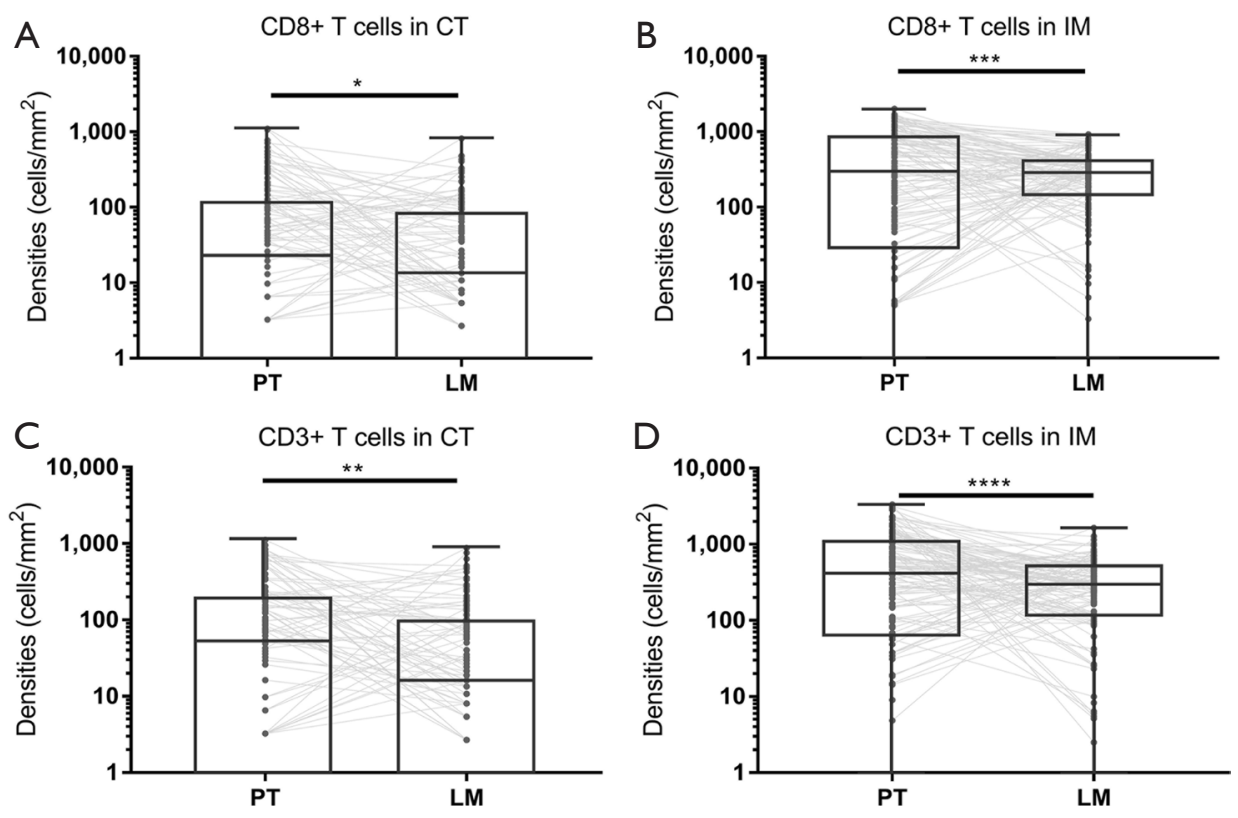

Figure 3 Densities of $\mathrm{CD}^{+}$and $\mathrm{CD}^{+} \mathrm{T}$ cells in CT and IM areas of primary tumors and corresponding liver metastases. Dark grey spots stand for $\mathrm{T}$ cells densities and the $\mathrm{T}$ cells densities of primary tumors and corresponding liver metastases are connected by light grey lines. (A) Densities of $\mathrm{CD}^{+} \mathrm{T}$ cells in the CT area, $\mathrm{P}=0.043$. (B) Densities of $\mathrm{CD}^{+} \mathrm{T}$ cells in the $\mathrm{IM}$ area, $\mathrm{P}<0.001$. (C) Densities of CD3 ${ }^{+} \mathrm{T}$ cells in the CT area, $\mathrm{P}=0.004$. (D) Densities of $\mathrm{CD}^{+} \mathrm{T}$ cells in the $\mathrm{IM}$ area, $\mathrm{P}<0.001$. ${ }^{*}, \mathrm{P}<0.05 ;{ }^{* *}, \mathrm{P}<0.01{ }^{* * *}, \mathrm{P}<0.001$; ${ }^{* * * *}, \mathrm{P}<0.0001$. CT, core tumor; IM, invasive margin.
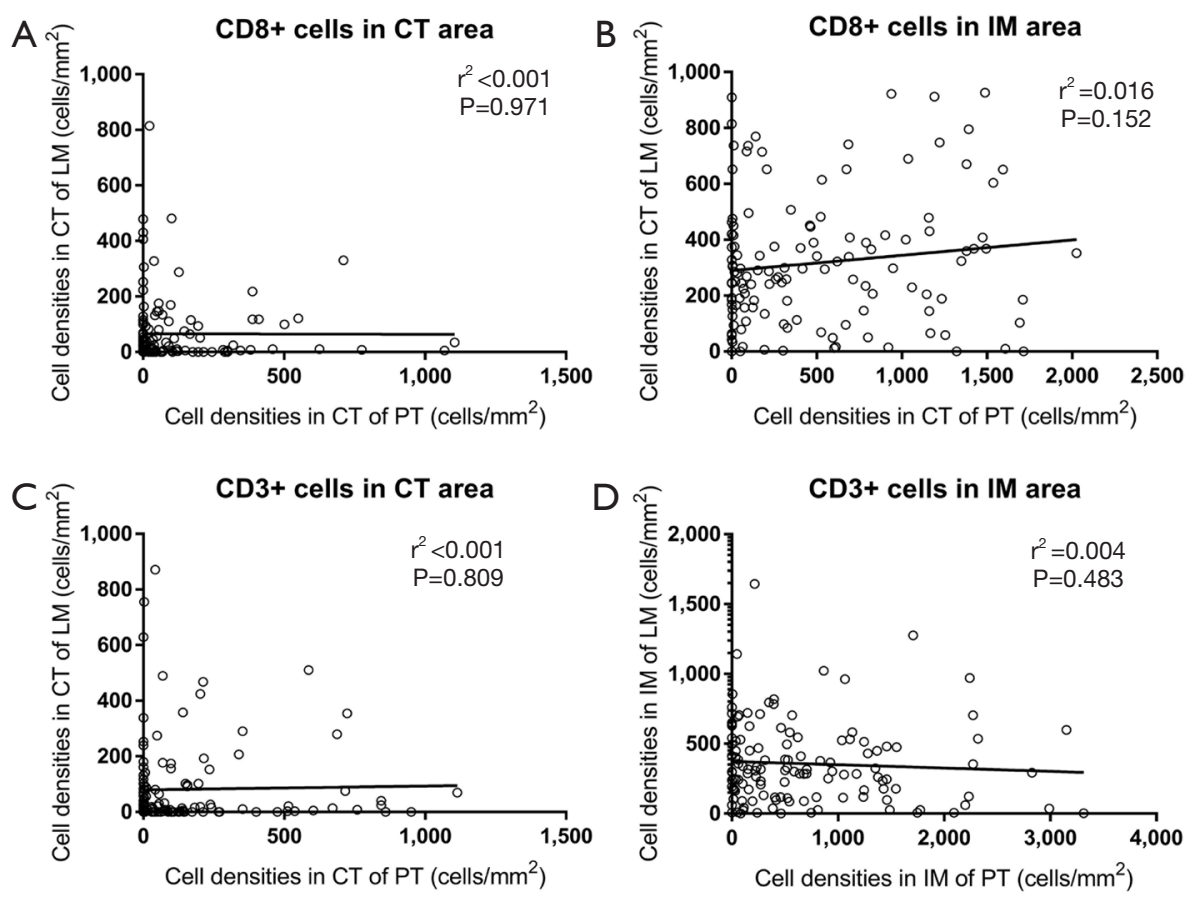

Figure 4 Correlation of lymphocyte densities between the colorectal primary tumor and liver metastases. (A,B) Correlation of CD8 ${ }^{+} \mathrm{T}$ cells in the CT and IM between colorectal primary tumors and liver metastases. (C,D) Correlation of CD8 ${ }^{+} \mathrm{T}$ cells in the CT and IM between colorectal primary tumors and liver metastases. CT, core tumor; IM, invasive margin. 

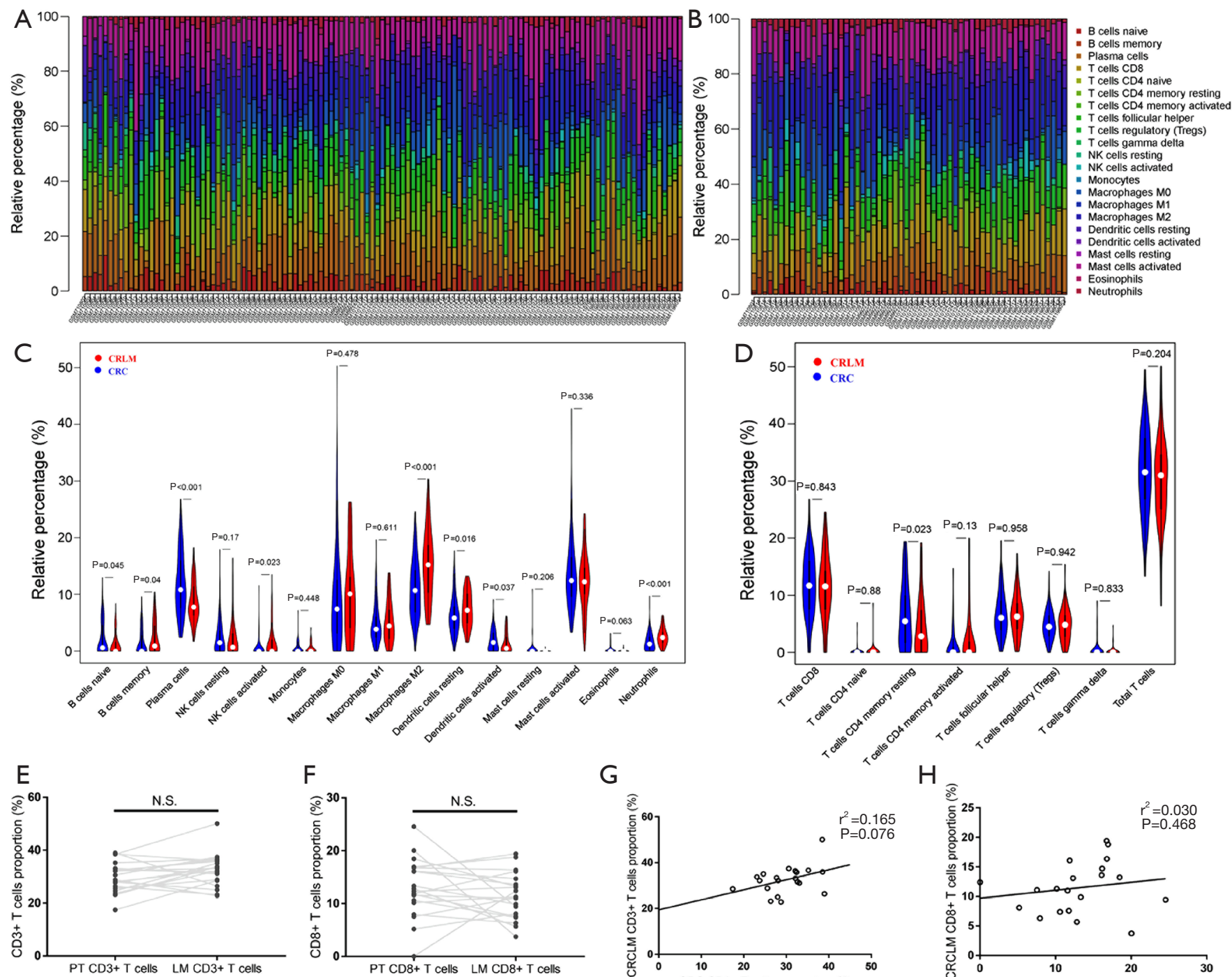

G
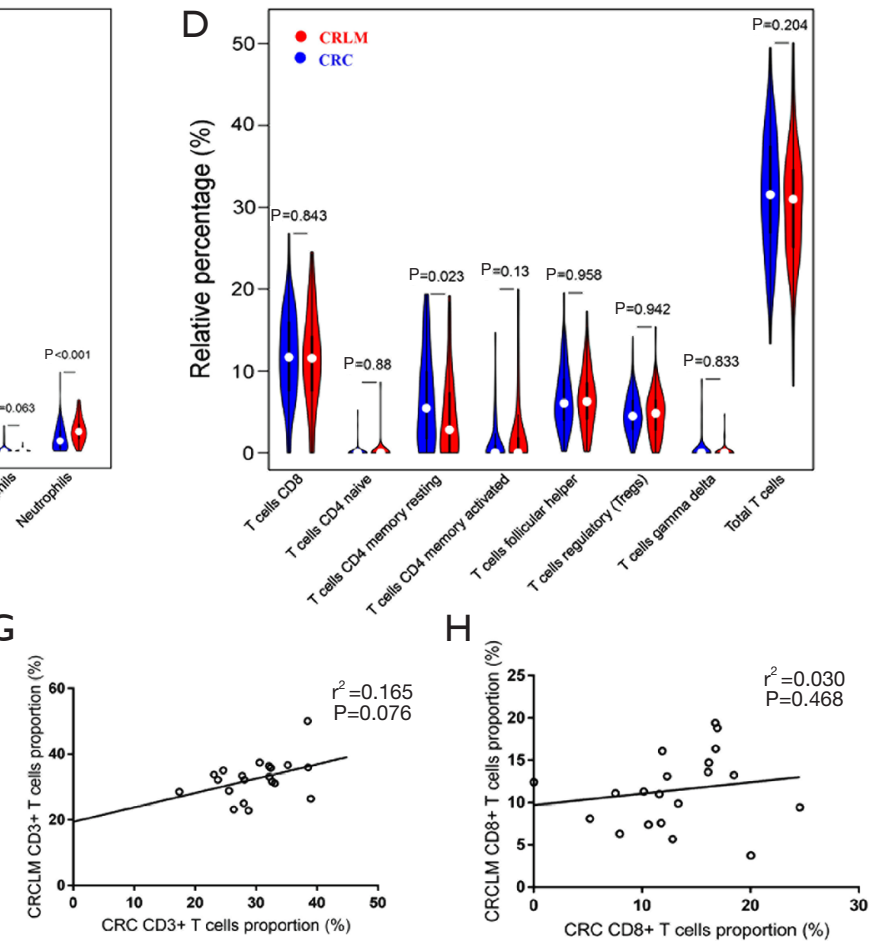

Figure 5 The proportions and correlations of immune cells between colorectal primary tumors and metastases analyzed by GEO dataset. (A,B) Bar graphs of the proportions of 22 subpopulations of immune cells obtained from 117 stage IV CRC primary sites (A) and 58 CRLM metastatic sites (B). (C,D) Violin graph of the proportions of immune cells between primary tumors and metastatic sites: (C) violin graph of the proportions of immune cells except for T cells; (D) violin graph of the proportions of T lymphocytes. (E,F,G,H) Difference and correlation of $\mathrm{CD}^{+}$and $\mathrm{CD} 8^{+} \mathrm{T}$ cell proportions between primary tumors and liver metastases in data collected from GEO: (E,F) difference in $\mathrm{CD}^{+}(\mathrm{E})$ and $\mathrm{CD}^{+}(\mathrm{F}) \mathrm{T}$ cell proportions between primary tumors and liver metastases, the dark grey dots represent the proportion of $\mathrm{CD}^{+} \mathrm{T}$ cells and $\mathrm{CD} 8^{+} \mathrm{T}$ cells of each case in primary tumor and liver metastasis. The proportions of CD $3^{+} \mathrm{T}$ cells and $\mathrm{CD} 8^{+} \mathrm{T}$ cells infiltrated in primary tumor and corresponding liver metastasis were connected by light grey lines $\left(\mathrm{CD} 3^{+}: \mathrm{P}=0.086, \mathrm{CD} 8^{+}: \mathrm{P}=0.282\right)$. $(\mathrm{G}, \mathrm{H})$ Correlation of $\mathrm{CD}^{+}(\mathrm{G})$ and $\mathrm{CD}^{+}(\mathrm{H}) \mathrm{T}$ cell proportions between primary tumors and liver metastases. CRC, colorectal cancer; CRLM, colorectal cancer liver metastases; GEO, Gene Expression Omnibus. 


\section{Conclusions}

The present study reveals that primary tumor immune score is not sufficient in predicting post-hepatectomy survival in Chinese patients with CRLM. Different immune infiltration exists between primary tumor and liver metastases.

\section{Acknowledgments}

We sincerely thank all the patients for their participation in this study. We are grateful to all colleagues in Sun Yat-sen University Cancer Center for their involvement in diagnosis and treatment of the patients.

Funding: This study was supported by the Science and Technology planning project of Guangdong province, China (201508020247), the National Natural Science Foundation of China (61503419), the Guangdong Natural Science Foundation (2014a030310355, 2016a030313234).

\section{Footnote}

Reporting Checklist: The authors have completed the TRIPOD reporting checklist. Available at http://dx.doi. org/10.21037/atm-20-4932

Peer Review File: Available at http://dx.doi.org/10.21037/ atm-20-4932

Conflicts of Interest: All authors have completed the ICMJE uniform disclosure form (available at http://dx.doi. org/10.21037/atm-20-4932). The authors have no conflicts of interest to declare. The authors declare no competing interest.

Ethical Statement: The authors are accountable for all aspects of the work in ensuring that questions related to the accuracy or integrity of any part of the work are appropriately investigated and resolved. The study was conducted in accordance with the Declaration of Helsinki (as revised in 2013) and its later amendments. The study was approved by institutional ethics board of Sun Yat-sen University Cancer Center (Registration number: GZR2019128) and individual consent for this retrospective analysis was waived.

Open Access Statement: This is an Open Access article distributed in accordance with the Creative Commons Attribution-NonCommercial-NoDerivs 4.0 International
License (CC BY-NC-ND 4.0), which permits the noncommercial replication and distribution of the article with the strict proviso that no changes or edits are made and the original work is properly cited (including links to both the formal publication through the relevant DOI and the license). See: https://creativecommons.org/licenses/by-nc-nd/4.0/.

\section{References}

1. Feng RM, Zong YN, Cao SM, et al. Current cancer situation in China: good or bad news from the 2018 Global Cancer Statistics? Cancer Commun (Lond) 2019;39:22.

2. Bray F, Ferlay J, Soerjomataram I, et al. Global cancer statistics 2018: GLOBOCAN estimates of incidence and mortality worldwide for 36 cancers in 185 countries. CA Cancer J Clin 2018;68:394-424.

3. Rudmik LR, Magliocco AM. Molecular mechanisms of hepatic metastasis in colorectal cancer. J Surg Oncol 2005;92:347-59.

4. Shah A, Alberts S, Adam R. Accomplishments in 2007 in the management of curable metastatic colorectal cancer. Gastrointest Cancer Res 2008;2:S13-8.

5. Wagner JS, Adson MA, Van Heerden JA, et al. The natural history of hepatic metastases from colorectal cancer. A comparison with resective treatment. Ann Surg 1984;199:502-8.

6. Adam R, Wicherts DA, de Haas RJ, et al. Patients with initially unresectable colorectal liver metastases: is there a possibility of cure? J Clin Oncol 2009;27:1829-35.

7. Leporrier J, Maurel J, Chiche L, et al. A populationbased study of the incidence, management and prognosis of hepatic metastases from colorectal cancer. Br J Surg 2006;93:465-74.

8. Ito K, Govindarajan A, Ito H, et al. Surgical treatment of hepatic colorectal metastasis: evolving role in the setting of improving systemic therapies and ablative treatments in the 21st century. Cancer J 2010;16:103-10.

9. Fong Y, Fortner J, Sun RL, et al. Clinical score for predicting recurrence after hepatic resection for metastatic colorectal cancer: analysis of 1001 consecutive cases. Ann Surg 1999;230:309-18; discussion 318-21.

10. Galon J, Pages F, Marincola FM, et al. Cancer classification using the Immunoscore: a worldwide task force. J Transl Med 2012;10:205.

11. Galon J, Mlecnik B, Bindea G, et al. Towards the introduction of the 'Immunoscore' in the classification of malignant tumours. J Pathol 2014;232:199-209.

12. Galon J, Fox BA, Bifulco CB, et al. Immunoscore 
and Immunoprofiling in cancer: an update from the melanoma and immunotherapy bridge 2015. J Transl Med 2016;14:273.

13. Mlecnik B, Van den Eynde M, Bindea G, et al. Comprehensive Intrametastatic Immune Quantification and Major Impact of Immunoscore on Survival. J Natl Cancer Inst 2018;110(1). doi:10.1093/jnci/djx123. Erratum in: J Natl Cancer Inst. 2018 Apr 1;110(4):438. doi: 10.1093/jnci/djy034.

14. Wang Y, Lin HC, Huang MY, et al. The Immunoscore system predicts prognosis after liver metastasectomy in colorectal cancer liver metastases. Cancer Immunol Immunother 2018;67:435-44.

15. Gabrielson A, Wu Y, Wang H, et al. Intratumoral CD3 and CD8 T-cell Densities Associated with Relapse-Free Survival in HCC. Cancer Immunol Res 2016;4:419-30.

16. Irizarry RA, Hobbs B, Collin F, et al. Exploration, normalization, and summaries of high density oligonucleotide array probe level data. Biostatistics 2003;4:249-64.

17. Newman AM, Liu CL, Green MR, et al. Robust enumeration of cell subsets from tissue expression profiles. Nat Methods 2015;12:453-7.

18. Ali HR, Chlon L, Pharoah PD, et al. Patterns of Immune Infiltration in Breast Cancer and Their Clinical Implications: A Gene-Expression-Based Retrospective Study. PLoS Med 2016;13:e1002194.

19. Shibutani M, Maeda K, Nagahara H, et al. A comparison of the local immune status between the primary and metastatic tumor in colorectal cancer: a retrospective study. BMC Cancer 2018;18:371.

20. Sobottka B, Pestalozzi B, Fink D, et al. Similar lymphocytic infiltration pattern in primary breast cancer and their corresponding distant metastases.

Cite this article as: Lin HC, Shao Q, Liang JY, Wang Y, Zhang HZ, Yuan YF, Li BK, Wu XJ, Chen G, Ding PR, Lu ZH, Pan ZZ, Wang DS, Qiu MZ, Wang ZQ, Wang FH, $\mathrm{Xu}$ RH, Li YH. Primary tumor immune score fails to predict the prognosis of colorectal cancer liver metastases after hepatectomy in Chinese populations. Ann Transl Med 2021;9(4):310. doi: 10.21037/atm-20-4932
Oncoimmunology 2016;5:e1153208.

21. Halama N, Spille A, Lerchl T, et al. Hepatic metastases of colorectal cancer are rather homogeneous but differ from primary lesions in terms of immune cell infiltration. Oncoimmunology 2013;2:e24116.

22. Van den Eynde M, Mlecnik B, Bindea G, et al. The Link between the Multiverse of Immune Microenvironments in Metastases and the Survival of Colorectal Cancer Patients. Cancer Cell 2018;34:1012-1026.e3.

23. Tong M, Deng Z, Zhang X, et al. New insights from the widening homogeneity perspective to target intratumor heterogeneity. Cancer Commun (Lond) 2018;38:17.

24. Halama N, Zoernig I, Spille A, et al. Quantification of prognostic immune cell markers in colorectal cancer using whole slide imaging tumor maps. Anal Quant Cytol Histol 2010;32:333-40.

25. Miranda E, Bianchi P, Destro A, et al. Genetic and epigenetic alterations in primary colorectal cancers and related lymph node and liver metastases. Cancer 2013;119:266-76.

26. Pancione M, Giordano G, Remo A, et al. Immune escape mechanisms in colorectal cancer pathogenesis and liver metastasis. J Immunol Res 2014;2014:686879.

27. Halama N, Michel S, Kloor M, et al. The localization and density of immune cells in primary tumors of human metastatic colorectal cancer shows an association with response to chemotherapy. Cancer Immun 2009;9:1.

28. Bayon LG, Izquierdo MA, Sirovich I, et al. Role of Kupffer cells in arresting circulating tumor cells and controlling metastatic growth in the liver. Hepatology 1996;23:1224-31.

29. Braet F, Nagatsuma K, Saito M, et al. The hepatic sinusoidal endothelial lining and colorectal liver metastases. World J Gastroenterol 2007;13:821-5. 


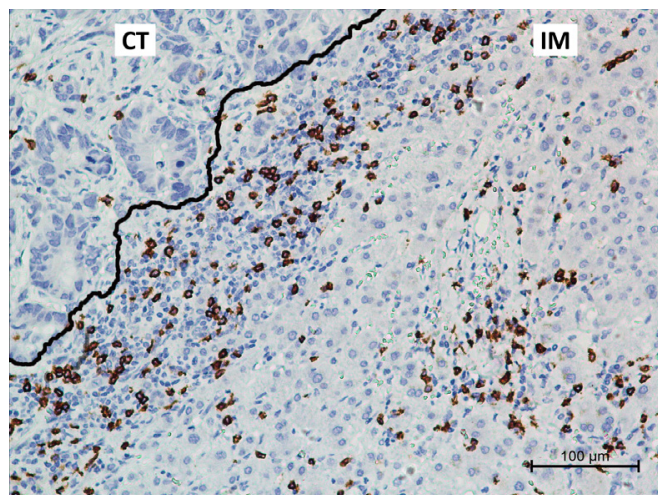

Figure S1 Representative picture delineating the boundary of CT and IM area in a liver metastasis specimen. The black line representing the borderline between CT and IM area. (scale bar $=100 \mu \mathrm{m})$. CT, core tumor; IM, invasive margin.

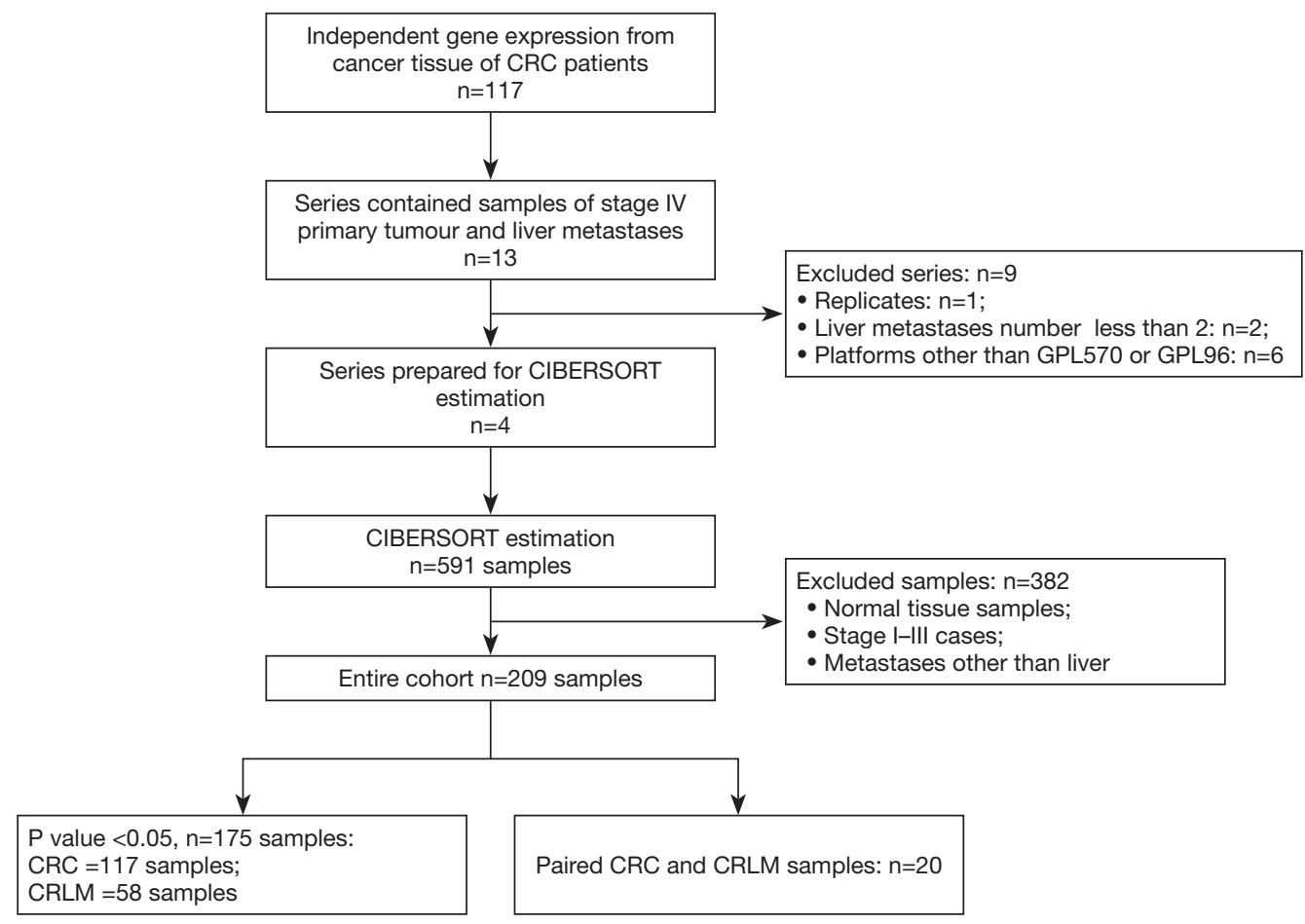

Figure S2 Flowchart of GEO dataset collection and sample selection. GEO, Gene Express Omnibus. 
Table S1 Median densities and interquartile ranges of the four indexes of immune score in primary tumor and liver metastasis

\begin{tabular}{lcc}
\hline \multirow{2}{*}{ Indexes } & Median densities of infiltrated lymphocytes $\left(\right.$ IQR) cells $/ \mathrm{mm}^{2}$ \\
\cline { 2 - 3 } & Primary tumor & liver metastases \\
\hline $\mathrm{CD}^{+}$cells in CT & $48.86(0.00-172.64)$ & $16.13(0.00-94.09)$ \\
$\mathrm{CD}^{+}$cells in IM & $417.40(62.20-1,066.04)$ & $300.00(118.71-524.40)$ \\
$\mathrm{CD}^{+}$cells in CT & $22.80(0.00-110.75)$ & $10.75(0.00-83.33)$ \\
$\mathrm{CD}^{+}$cells in IM & $302.20(26.22-828.67)$ & $290.63(149.02-419.56)$ \\
\hline
\end{tabular}

CT, core tumor; IM, invasive margin; IQR, interquartile range.

Table S2 Median densities and interquartile ranges of the four indexes in primary tumors according to patients clinicopathological characteristics

\begin{tabular}{|c|c|c|c|c|}
\hline Characteristics & \multicolumn{4}{|c|}{ Median density (IQR) cells $/ \mathrm{mm}^{2}$} \\
\hline \multicolumn{5}{|l|}{ Synchronous metastases } \\
\hline Present & $50.49(0.00-175.08)$ & $411.40(77.31-1,049.43)$ & $24.43(0.00-112.38)$ & 304.16 (30.92-846.88) \\
\hline Absent & $39.09(0.00-169.38)$ & $459.18(7.43-1,330.57)$ & $9.77(0.00-148.21)$ & 123.97 (16.12-928.90) \\
\hline Yes & $97.72(1.63-309.45)$ & $540.67(150.04-1,190.09)$ & 71.66 (17.92-294.79) & $500.00(87.46-1,151.66)$ \\
\hline No & $9.77(0.00-140.07)$ & $268.56(36.50-1,058.51)$ & $6.51(0.00-50.49)$ & $159.44(9.54-714.72)$ \\
\hline \multicolumn{5}{|l|}{ Primary tumor location } \\
\hline Right-sided & $26.06(0.00-175.08)$ & $406.13(77.31-976.46)$ & $35.83(0.00-86.32)$ & 226.63 (13.17-699.14) \\
\hline Synchronous resection & $42.35(0.00-201.95)$ & $394.87(107.48-1,047.24)$ & $22.80(0.00-117.26)$ & 295.77 (26.22-901.52) \\
\hline Heterochronous resection & $55.37(0.00-145.77)$ & $479.87(32.77-1,128.26)$ & $21.17(0.00-109.12)$ & 313.57 (24.12-815.42) \\
\hline
\end{tabular}

$\mathrm{CT}$, core tumor; IM, invasive margin; IQR, interquartile range. 
Table S3 All regression coefficients in multivariate Cox regression analyses in Tables 3,4

\begin{tabular}{lc}
\hline Characteristics & Regression coefficients \\
\hline Age (>65 s vs. $\leq 65$ years) & 1.183 \\
Gender (male vs. female) & 1.664 \\
BMI ( $\geq 24$ vs. $<24$ kg/m²) & 1.359 \\
Primary tumor grade (G3 vs. G1-2) & 1.260 \\
Primary tumor location (right-sided vs. left-sided) & 1.771 \\
T-stage (pT4 vs. pT1-3) & 1.450 \\
N-stage (pN1-2 vs. pN0) & 1.611 \\
Synchronous metastases (present vs. absent) & 1.130 \\
Resection status (heterochronous vs. synchronous) & 0.458 \\
Preoperative chemotherapy before primary tumor & 0.405 \\
resection (yes vs. no) & \\
Immune score LM (high vs. low) & 0.427 \\
Immune score PT (high vs. low) & 0.389 \\
\hline
\end{tabular}

BMI, body mass index; LM, liver metastases; PT, primary tumor. 